\title{
The changing face of dentistry: nanotechnology
}

This article was published in the following Dove Press journal:

International Journal of Nanomedicine

8 November 2011

Number of times this article has been viewed

\author{
Rosaiah Kanaparthy' \\ Aruna Kanaparthy ${ }^{2}$ \\ 'Department of Periodontics, \\ ${ }^{2}$ Conservative Dentistry, \\ Peoples Dental Academy, Bhopal, \\ Madhya Pradesh, India
}

Correspondence: Rosaiah Kanaparthy Department of Periodontics, Peoples Dental Academy, Bhopal, Madhya Pradesh, HIG-3, PDA Staff Quarters,

Peoples Campus, Bhanpur, Bhopal,

Madhya Pradesh, India

Mob +9l 9893050554

Email medha98@gmail.com

\begin{abstract}
The human body comprises molecules; hence, the availability of molecular nanotechnology will permit dramatic progress to address medical problems and will use molecular knowledge to maintain and improve human health at the molecular scale. Nanomedicine could develop devices that are able to work inside the human body in order to identify the early presence of a disease, and to identify and quantify toxic molecules and tumor cells, for example. Nanodentistry will make possible the maintenance of comprehensive oral health by employing nanomaterials, including tissue engineering and, ultimately, dental nanorobots. This review is an attempt to highlight the possible applications of nanotechnology and the use of nanomaterials in dentistry.
\end{abstract}

Keywords: nanotechnology, molecule, nanomedicine, nanodentistry, nanorobots

\section{Introduction}

The only thing that is constant in life is change. Two pivotal changes have transformed scientific medicine from a merely rational basis to a molecular basis. The first pivotal event was the drug revolution; the second pivotal event was the genetics revolution, starting with the discovery in 1953 of the information-carrying double-helix structure of DNA by Francis Crick and John B Watson. In the mid-1980s the Human Genome Project was launched, with the objective of fully sequencing every gene in the human genome. The first phase of this project neared completion as the 20th century drew to a close. Thus, the late 20th century is best regarded as the molecular age of basic biological science. The molecular influence pervades all the traditional disciplines underlying clinical medicine.

The tremendously growing scientific and innovative research, which is resulting in the trend of an aging population in both developed and developing countries, is provoking scientists to concentrate on the field of regenerative medicine and tissue engineering to look continuously for newer ways to apply the principles of cell transplantation and bioengineering to construct a biological substitute that will restore and maintain the normal function in diseased and injured tissues. ${ }^{1}$

In 1959 the late Nobel Prize-winning physicist Richard P Feynman presented a talk entitled "There's plenty of room at the bottom" at the annual meeting of the American Physical Society at the California Institute of Technology, Pasadena, CA.

One nanometer is one-billionth or $10^{-9}$ of a meter. To put that scale in context, the comparative size of a nanometer to a meter is the same as that of a marble to the size of the earth. Or the other way of putting it is that a nanometer is the amount a man's beard grows in the time it takes him to raise the razor to his face..$^{2-5}$ 


\section{Nanomaterial properties}

Nanomaterials are of interest from a fundamental point of view because with new materials, come new properties, which result in new opportunities for technological and commercial development, and applications of nanoparticles have been proposed in areas as diverse as microelectronics, coatings and paints, and biotechnology. From these applications has come the development of nanopharmaceuticals, nanosensors, nanoswitches, and nanodelivery systems.

Two principal factors cause the properties of nanomaterials to differ significantly from other materials: the increase in relative surface area and quantum effects. For example, a particle of $30 \mathrm{~nm}$ has $5 \%$ of its atoms on its surface, at $10 \mathrm{~nm}$ $20 \%$ of its atoms, and at $3 \mathrm{~nm} 50 \%$ of its atoms. Nanoparticles have a much greater surface area per unit mass compared with larger particles. ${ }^{6}$

In tandem with surface area effects, quantum effects can begin to dominate the properties of matter, as size is reduced to the nanoscale it can affect the optical, electrical, and magnetic behavior of materials, particularly as the structure or particle size approaches the smaller end of the nanoscale. For example, nanocrystalline nickel is as strong as hardened steel. ${ }^{6}$

\section{The applications of nanotechnology}

The applicative utility of the field of nanotechnology can be seen in various fields like: ${ }^{7}$

- Medicine

- Diagnostics

- Drug delivery

- Tissue engineering

- Chemistry and environment

- Catalysis

- Filtration

- Energy

- Reduction of energy consumption

- Increasing the efficiency of energy production

- The use of more environmentally friendly energy systems

- Recycling of batteries

- Information and communication

- Novel semiconductor devices

- Novel optoelectronic devices

- Displays

- Quantum computers

- Heavy industry

- Aerospace

- Refineries

- Vehicle manufacturers
- Consumer goods

- Foods.

\section{Nanomedicine}

"Nanomedicine" is the science of preventing, diagnosing, and treating disease and preserving and improving human health, using nanosized particles..$^{7-9}$

\section{Medical nanorobots}

Nanorobots have a diameter of about $0.5-3$ microns and will be constructed of parts with dimensions in the range of 1-100 nanometers. The main element used will be carbon in the form of diamond/fullerene.

Programmable nanorobotic devices would allow physicians to perform precise interventions at the cellular and molecular level.

Medical nanorobots have been proposed for gerontological applications in pharmaceutical research, clinical diagnosis, and dentistry, and also for mechanically reversing atherosclerosis, improving respiratory capacity, enabling near-instantaneous homeostasis, supplementing the immune system, rewriting or replacing DNA sequences in cells, repairing brain damage, and resolving gross cellular insults whether caused by an irreversible process or by cryogenic storage of biological tissues.

Nanosensors have been developed for military use in recognizing airborne rogue agents and chemical weapons and to detect drugs and other substances in exhaled breath. Drug abuse like marijuana, concentration of alcohol, testing of athletes for banned substances, and individuals' drug treatment programs are areas that are long overdue for breath detection technologies.

\section{Implantable materials ${ }^{10}$}

This technology can be used in the following areas:

- Tissue repair and replacement

- Implant coatings

- Tissue regeneration scaffolds

- Structural implant materials

- Bone repair

- Bioresorbable materials

- Smart materials

- Assessment and treatment devices

- Sensory aids

- Retinal and cochlear implants.

\section{Types of nanotechnologies}

Broadly, nanotechnologies consist of three mutually overlapping and progressively more powerful molecular technologies: 
- Nanoscale-structured materials and devices that can be fabricated for advanced diagnostics and biosensors, targeted drug delivery, and smart drugs

- Molecular medicine via genomics, proteomics, artificial biobotics (microbial robots)

- Molecular machine systems and medical nanorobots allow instant pathogen diagnosis and extermination, and efficient augmentation and improvement of natural physiological function.

\section{Nanophase materials"I}

Nanophase materials are promising materials for various bioapplications, because human tissues are composed of nanometer components (proteins, inorganics).

\section{Nanophase hydroxy apatite}

The adhesion and proliferation of osteoblasts are significantly greater on nanophase hydroxy apatite (HA) than on conventional HA. Therefore, nanophase HA clearly represents a unique and promising class of maxillofacial implant formulations with improved osseointegrative properties. Apart from nanostructured HA, both nanophase alumina and titania demonstrate the same properties. HA nanoparticles used to treat bone defects are Ostim HA (Osartis $\mathrm{GmbH}$, Germany). Vitosso (Orthovita, Inc) HA + TCP (tricalcium phosphate), and NanOSSTM HA (Angstrom Medica).

\section{Nanophase carbon}

Carbon nanofibers have exceptional theoretical mechanical properties that, along with possessing nanoscale fiber dimensions similar to crystalline HA found in bone, suggest strong possibilities for use as a maxillofacial implant material.

\section{Possible applications of nanotechnology in dentistry ${ }^{12}$ Local anesthesia}

In the area of nanodentistry, a colliodal suspension containing millions of active analgesic micron-size dental robots will be instilled on the patient's gingiva which will result in anesthesia.

\section{Hypersensitivity cure}

Dentin hypersensitivity may be caused by changes in pressure transmitted hydrodynamically to the pulp. This is based on the fact that hypersensitive teeth have eight times higher surface density of dentinal tubules and tubules with diameters twice as large as nonsensitive teeth. Dental nanorobots could selectively and precisely occlude selected tubules in minutes, using native logical materials, offering patients a quick and permanent cure.

\section{Nanorobotic dentifrice (dentifrobots)}

Subocclusal-dwelling nanorobotic dentifrice delivered by mouthwash or toothpaste could patrol all supragingival and subgingival surfaces at least once a day, metabolizing trapped organic matter into harmless and odorless vapors and performing continuous calculus debridement. Dentifrobots are invisibly small (1-10 micron), with 103-105 nanodevices/ oral cavity, crawling at 1-10 microns/second.

\section{Dental durability and cosmetics}

Tooth durability and appearance can be improved by replacing upper enamel layers with pure sapphire and diamond, which can be made more fracture resistant as nanostructured composites, possibly including embedded carbon nanotubes.

\section{Tooth repair}

Nanorobotic manufacture and installation of a biologically autologous whole replacement tooth that includes both mineral and cellular components (ie, complete dentition replacement therapy) should become feasible within the time and economic constraints of a typical office visit through the use of an affordable desktop manufacturing facility, which would fabricate the new tooth in the dentist's office.

Chen et al ${ }^{13}$ took advantage of these latest developments in the area of nanotechnology to simulate the natural biomineralization process to create the hardest tissue in the human body, dental enamel, by using highly organized microarchitectural units of nanorod-like calcium HA crystals arranged roughly parallel to each other.

\section{Tooth renaturalization}

This procedure may become popular and provide perfect treatment methods for esthetic dentistry. This trend may begin with patients who desire to have their old dental amalgams excavated and their teeth remanufactured with native biological materials, and full coronal renaturalization procedures in which all fillings, crowns, and other 20th century modifications to the visible dentition are removed, with the affected teeth remanufactured to become indistinguishable from original teeth.

\section{Photosensitizers and carriers}

"Quantum dot" nanocrystals are tiny particles measuring only a few nanometers across, about the same size as a protein 
molecule or a short sequence of DNA. Quantum dots can be used as photo sensitizers and carriers.

\section{Diagnosis of oral cancer ${ }^{14-16}$ Nanoscale cantilevers}

These are flexible beams resembling a row of diving boards that can be engineered to bind to molecules associated with cancer.

\section{Nanopores}

These are tiny holes that allow DNA to pass through one strand at a time. They will make DNA sequencing more efficient.

\section{Nanotubes}

These are carbon rods about half the diameter of a molecule of DNA that not only can detect the presence of altered genes but also may help researchers pinpoint the exact location of those changes.

\section{Quantum dots}

Quantum dots are nanomaterials that glow very brightly when illuminated by ultraviolet light. They can be coated with a material that makes the dots attach specifically to the molecule to be tracked. Quantum dots bind themselves to proteins unique to cancer cells, literally bringing tumors to light.

\section{Nanoelectromechanical systems/ cantilever array sensors}

\section{Dendrimers}

These are highly branched macromolecules with a controlled three-dimensional architecture. The branched structure makes it possible to attach other molecules like drugs and contrast agents to the surface.

\section{Nanoshells}

These are miniscule beads coated with gold. By manipulating the thickness of the layers making up the nanoshells, scientists can design these beads to absorb near-infrared light, creating an intense heat that is lethal to cancer cells. Nanoshells have a core of silica and a metallic outer layer.

\section{Treatment of oral cancer}

Options include the following:

- Nanomaterials for brachy therapy

- BrachySil $^{\mathrm{TM}}$ delivers 32P
- Drug delivery across the blood-brain barrier/more effective treatment of brain tumors, Alzheimer's disease, and Parkinson's disease

- Nanovectors for gene therapy

- Nonviral gene delivery systems

\section{Nanomaterials in dentistry ${ }^{13}$ Nanocomposites}

The particle size of conventional composites are so dissimilar to the structural sizes of the HA crystal, dentinal tubule, and enamel rods that there is a potential for compromise in adhesion between the macroscopic $(40 \mathrm{~nm}-0.7 \mathrm{~nm})$ restorative material and the nanoscopic ( $1 \mathrm{~nm}-10 \mathrm{~nm}$ in size) tooth structure. Nanocomposite systems have the potential to improve this continuity between the tooth structure and the nanosized filler particle and provide a more stable and natural interface between the mineralized hard tissues of the tooth and these advanced restorative biomaterials. Nanotechnology or molecular manufacturing may provide composite resin with filler particles that are dramatically smaller, can be dissolved in higher concentrations, and are polymerized into the resin system with molecules designed to be compatible when coupled with a polymer, and provide unique physical, mechanical, and optical characteristics. ${ }^{17}$

The mineral component of the composite, which is a filler, is termed "the dispersed phase" and has been noticeably improved with the addition of small particles or fillers. ${ }^{18}$ In dental composites, fillers provide strength and reinforcement to the matrix. ${ }^{19,20}$

One such nanocomposite system (Premise, Kerr/ Sybron, Orange, CA) is composed of three different types of filler components: nonagglomerated "discrete" silica nanoparticles, barium glass, and prepolymerized filler.

Nanoproducts Corporation has successfully manufactured nonagglomerated coatings to produce nanocomposites. The nanofiller used includes an aluminosilicate powder with a mean particle size of $80 \mathrm{~nm}$ and a 1:4 $\mathrm{M}$ ratio of alumina to silica and a refractive index of 1.508 .

Advantages include:

- Superior hardness

- Superior flexural strength, modulus of elasticity, and translucency

- $50 \%$ reduction in filling shrinkage

- Excellent handling properties.

\section{Nanosolution}

Nanosolutions produce unique and dispersible nanoparticles, which can be used in bonding agents (trade name: Adper Single Bond Plus Adhesive Single Bond). 


\section{Impression materials}

Nanofillers are integrated in vinyl polysiloxanes, producing a unique addition of siloxane impression materials.

\section{Nanoencapsulation}

South West Research Institute (SWRI) has developed targeted release systems that encompass nanocapsules including novel vaccines, antibiotics, and drug delivery with reduced side effects.

Other products manufactured by SWRI include:

- Protective clothing and filtration masks, using antipathogenic nanoemulsions and nanoparticles

- Medical appendages for instantaneous healing: biodegradable nanofiber delivery platforms for hemostatic wound dressings are in development along with nanocrystalline silver particles with antimicrobial properties on wound dressings

- Bone targeting nanocarriers: calcium phosphate-based biomaterial has been developed, which is an easily flowable, moldable paste that conforms to and interdigitates with host bone.

\section{Nanoneedles}

Suture needles incorporating nano-sized stainless steel crystals have been developed (trade name: Sandvik Bioline, RK 91 needles, AB Sandvik, Sweden). Nanotweezers are also under development, which will make cell surgery possible in the near future.

\section{Bone replacement materials ${ }^{21}$}

Bone is a natural nanostructured (ie, a material with constituent features less than $100 \mathrm{~nm}$ in at least one dimension) composite composed of organic compounds (mainly collagen) reinforced with inorganic ones (HA). It is this natural nanostructure that nanotechnology aims to emulate for orthopedic and dental applications. The smaller the particle is, the larger the surface area is in volume. Nano-Bone ${ }^{\circledR}$ uses this principle. The nanocrystallites show a loose microstructure, with nanopores situated between the crystallites. This material structure will be completed by pores in the micrometer area. By following this process, a rough surface area is formed on the boundary layer between the biomaterial and cell, which is very important for fast cell growth. Porosity values of around $60 \%$ can be found in both the nano- and the micrometer pores. All pores are interconnecting (ie, by being in contact with the patient's blood, bodily substances merge into the pores). Because the cells are too big for the small pores, blood plasma containing all the important proteins is retained in the interstices. The surface of the pores (and also of the nanopores) is modified in such a way that it literally "hangs on" to the proteins. This is to be carried out by silica molecules. The compound silica is most important.

Special features of bone graft materials are as follows:

- Osteoinductive

- Fully synthetic

- Not sintered

- Highly porous

- Nanostructured

- Absorbs natural body-produced proteins into the nanopores

- Degradation by osteoclasts

- Very good processability

- No ionic solution products

\section{Discussion and conclusion}

Although it is easy to get carried away by the infinite possibilities in the use and application of nanotechnology, we must remind ourselves of the need to address the following issues.

\section{Gaps in knowledge}

The associated risks of using nanoparticles are not yet clear and therefore one needs to exert caution in using them.

\section{Nanoparticle biocompatibility}

Toxicity of nanoparticles cannot be predicted from the toxicity known for the chemical entity itself.

\section{Economics}

Nanotechnology should be cost effective.

\section{Disclosure}

The authors report no conflicts of interest in this work.

\section{References}

1. Atala A. Technology insight: application tissue engineering and biological substitutes in urology. Nat Clin Pract Urol. 2005;2:143-149.

2. Taniguchi N. On the basic concept of 'nano-technology'. Proceeding of the International. Conference on Production Engineering; 1974.

3. Schleyer TL. Nanodentistry: fact or fiction? J Am Dent Assoc. 2000;131: 1567-1568.

4. Feyman R. There is Plenty of Room at the Bottom: Miniaturization. New York: Reinhold; 1961:282-296.

5. Kahn J. Nano's big future: nanotechnology. National Geographic. 2006:98-119.

6. Drexler KE. Nanosystems: Molecular Machinery Manufacturing and Computation. New York: John Wiley and Sons; 2006.

7. European Science Foundation (ESF). Nanomedicine: forward look on nanomedicine. Available from: http://www.esf.org/publications/forwardlooks.html. Accessed on October 5, 2011. 
8. Kubik T, Bogunia K, Sugisaka M. Nanotechnology on duty in medical applications. Curr Pharm Biotechnol. 2005;6:17-33.

9. Drexler KE, Peterson C. Unbounding the Future: The Nanotechnology Revolution. New York: William Morrow/Onill Books; 1991.

10. Gordon N, Sagman U, Borm P, et al. The Potential Risks of Nanomaterials: A Review Carried Out Canadian Nano Business Alliance, Nanotechnology Research and Development in Canada, February 2008 and 2009

11. Webster TJ, Ergun C, Doremus RH, et al. Enhanced osteoclastlike cell functions on nanophase ceramics. Biomaterials. 2001;22: 1327-1333.

12. Freitas Jr RA. Nanodentistry. J Am Dent Assoc. 2000;131:1559-1566.

13. Chen Y, Jung G-Y, Ohlberg DAA, et al. Nanoscale molecular-switch crossbar circuits. Nanotechnology. 2003;14:462.

14. Khosla R. Nanotechnology in dentistry. Famdent Practical Dentistry Handbook. 2009;9:69-84.

15. Weiss R. Nanomedicine's promise is anything but tiny. Washington Post. January $30,2005$.
16. Kairemo K, Erba P, Bergstrom K, Pauwels EJ. Nanoparticles in cancer. Curr Radiopharm. 2008;1:30-36.

17. Terry DA. Direct applications of a nanocomposite resin system: Part $1-$ The evolution of contemporary composite materials. Pract Proced Aesthet Dent. 2004;16:417-422.

18. Iga M, Takeshige F, Ui T, Torii M. The relationship between polymerization shrinkage measured by a modified dilatometer and the inorganic filler content of light-cured composites. Dent Mater J. 1991; 10:38-45.

19. Munksgaard EC, Hansen EK, Kato H. Wall-to-wall polymerization contraction of composite resins versus filler content. Scand J Dent Res. 1987;95:526-531.

20. Lutz F, Setcos JC, Phillips RW, Roulet JF. Dental restorative resins. Types and characteristics. Dent Clin North Am. 1983;27:699-712.

21. Piñón-Segundo E, Ganem-Quintanar A, Alonso-Pérez V, QuintanarGuerrero D. Preparation and characterization of triclosan nanoparticles for periodontal treatment. Int J Pharm. 2005;294(1-2):217-232.
International Journal of Nanomedicine

\section{Publish your work in this journal}

The International Journal of Nanomedicine is an international, peerreviewed journal focusing on the application of nanotechnology in diagnostics, therapeutics, and drug delivery systems throughout the biomedical field. This journal is indexed on PubMed Central, MedLine, CAS, SciSearch ${ }^{\circledR}$, Current Contents ${ }^{\circledR} /$ Clinical Medicine,

\section{Dovepress}

Journal Citation Reports/Science Edition, EMBase, Scopus and the Elsevier Bibliographic databases. The manuscript management system is completely online and includes a very quick and fair peer-review system, which is all easy to use. Visit http://www.dovepress.com/ testimonials.php to read real quotes from published authors. 